\title{
Peningkatan Keamanan Pesan Berbasis Android Menggunakan Algoritma Kriptografi RSA
}

\author{
Rahmat Sulaiman ${ }^{1}$, Marina Vebu ${ }^{2}$ \\ Dosen Teknik Informatika ${ }^{1}$, Mahasiswa Teknik Informatika, ${ }^{2}$ \\ STMIK Atma Luhur ${ }^{1,2}$ \\ J1. Jend. Sudirman, Selindung Baru, Pangkalpinang \\ e-mail: $\underline{\text { rahmatsulaiman@ @atmaluhur.ac.id }}{ }^{1}, \underline{1411500166 @ \text { mahasiswa.atmaluhur.ac.id }^{2}}$
}

\begin{abstract}
Abstrak - Keamanan dan kerahasiaan sebuah data atau informasi merupakan hal yang sangat penting, baik dalam suatu organisasi seperti perusahaan, perguruan tinggi, maupun individual. Itu dikarenakan seringkali data atau informasi yang penting kadang tidak sampai ke tangan si penerima atau juga bisa sampai ke tangan si penerima tapi data yang diterima tersebut disadap terlebih dahulu tanpa sepengetahuan pengirim maupun penerima itu sendiri. Untuk mengatasi masalah yang ada, peneliti akan membuat suatu aplikasi peningkatan keamanan pesan berbasis android menggunakan algoritma kriptografi RSA yang akan di implementasikan untuk aplikasi pesan pada smartphone android. Aplikasi ini digunakan untuk mengirim dan menerima pesan pada smartphone berbasis android dengan mengamankan atau menyembunyikan pesan asli. Metode yang digunakan Adalah algoritma kriptografi RSA yang menggunakan dua kunci berbeda dalam melakukan enkripsi dan dekripsi yaitu kunci publik untuk enkripsi dan kunci privat untuk dekripsi. Algoritma kriptografi RSA ditambahkan dalam aplikasi ini guna meningkatkan keamanan pesan berbasis android dengan menerapkan algoritma RSA dalam proses mengenkripsikan pesan dengan menggunakan key yang berupa angka-angka yang telah ditentukan pengirim, dan mendekripsikan pesan yang dikirim menjadi pesan asli, sehingga pesan tersebut cukup aman dan tidak akan terbaca oleh pihak yang tidak mempunyai hak atas pesan tersebut.
\end{abstract}

Kata Kunci - Android, Algoritma RSA, Kriptografi, Keamanan, Pesan

\section{PENDAHULUAN}

Keamanan dan kerahasiaan sebuah data atau informasi merupakan hal yang sangat penting, baik dalam suatu organisasi seperti perusahaan, perguruan tinggi, maupun individual. Itu dikarenakan seringkali data atau informasi yang penting kadang tidak sampai ke tangan si penerima atau juga bisa sampai ke tangan si penerima tapi data yang diterima tersebut disadap terlebih dahulu tanpa sepengetahuan pengirim maupun penerima itu sendiri. Dan bisa saja data asli tersebut dirubah menjadi data yang tidak sesuai, sehingga dapat menjatuhkan pihak si pengirim. Padahal data sebenarnya tidak seperti itu. Kriptografi dan steganografi merupakan ilmu atau seni yang mempelajari pengamanan pesan atau data dan kerahasiaan pesan atau data. Dalam kriptografi, terdapat 2 proses utama, enkripsi dan dekripsi. Enkripsi adalah proses penyandian pesan asli atau plainteks menjadi cipherteks (teks tersandi). Sedangkan dekripsi adalah proses penyandian kembali cipherteks menjadi plainteks [1,2].

Salah satu usaha untuk mengamankan data diantaranya dengan menggunakan kriptografi. Algoritma kriptografi yang sering digunakan dalam proses pengamanan data yaitu algoritma RSA. Algoritma RSA adalah algoritma yang mudah untuk di implementasikan dan dimengerti [2,3].

\section{LANDASAN TEORI}

\section{A. Model Perangkat Lunak RAD (Rapid Application Development)}

RAD adalah suatu pendekatan berorientasi objek terhadap pengembangan sistem yang mencakup suatu metode pengembangan serta perangkat-perangkat lunak. RAD bertujuan mempersingkat waktu yang biasanya diperlukan dalam siklus hidup pengembangan sistem tradisional antara perancangan dan penerapan suatu sistem informasi. Pada akhirnya, RAD samasama berusaha memenuhi syarat-syarat bisnis yang berubah secara cepat.

\section{B. Algoritma RSA}

Untuk mengamankan data, salah satu cara dapat diterapkan suatu algoritma kriptografi untuk melakukan enkripsi. Dengan enkripsi data tidak dapat terbaca karena teks asli atau plaintext telah diubah ke teks yang tak terbaca atau disebut chipertext. Ada banyak algoritma kriptografi yang dapat digunakan, berdasarkan sifat kuncinya dibagi menjadi dua yaitu simetris yang hanya memakai satu kunci rahasia dan asimetris (public key algorithm) yang memakai sepasang kunci publik dan kunci rahasia [3,4]. Pada penelitian ini algoritma kriptografi yang akan digunakan adalah algoritma kriptografi asimetris RSA yang ditemukan oleh Ron Rivest, Adi Shamir, dan 
Leonard Adleman pada tahun 1978 dan RSA merupakan singkatan inisial dari nama mereka bertiga. RSA digunakan karena merupakan algoritma kriptografi asimetris yang paling sering digunakan pada saat ini dikarenakan kehandalannya. Panjang kunci dalam bit dapat diatur, dengan semakin panjang bit maka semakin sukar untuk dipecahkan karena sulitnya memfaktorkan dua bilangan yang sangat besar tersebut, tetapi juga semakin lama pada proses dekripsinya [6].

Algoritma RSA dibuat oleh 3 orang peneliti dari MIT (Massachussets Institute of Technology) pada tahun 1976, yaitu: Ron (R)ivest, Adi (S)hamir, dan Leonard (A)dleman .Keamanan algoritma RSA terletak pada sulitnya memfaktorkan bilangan yang besar menjadi faktor-faktor prima. Pemfaktoran dilakukan untuk memperoleh kunci pribadi. Selama pemfaktoran bilangan besar menjadi faktor-faktor prima belum ditemukan algoritma yang mangkus, maka selama itu pula keamanan algoritma RSA tetap terjamin $[4,5]$.

\section{Prosedur Membuat Pasangan Kunci}

- Pilih dua buah bilangan prima sembarang, $p$ dan $q$.

- Hitung $r=p \times q$. Sebaiknya $p^{1} q, \quad$ sebab jika $p=q$ maka $r=p^{2}$ sehingga $p$ dapat diperoleh dengan menarik akar pangkat dua dari $r$.

- Hitung $\mathrm{f}(r)=(p-1)(q-1)$.

- Pilih kunci publik, $P K$, yang relatif prima terhadap $\mathrm{f}(r)$.

- Bangkitkan kunci rahasia dengan menggunakan persamaan (5), yaitu $S K \times P K^{\circ} 1(\bmod \mathrm{f}(r))$.

\section{Pengembangan Sistem Berorientasi Objek dengan $U M L$}

UML dibangun dari diagram-diagram yang dapat digunakan untuk memodelkan sebuah sistem dari berbagai sudut pandang waktu yang berbeda dalam daur hidup perangkat lunak sebuah sistem. OOSE dikembangkan oleh Ivar Jacobson adalah metode desain berorientasi objek yang melibatkan use case. Use case Merupakan skenario untuk memahami requirement user terhadap sistem menggambarkan interaksi antara user dengan sistem, menggambarkan tanggung jawab dan keluaran sistem pada pengguna dapat digambarkan dengan teks tanpa aliran kejadian, teks dengan aliran data, dan formal dengan pseudo code. Metode yang paling banyak digunakan adalah menggunakan UML (Unified Modelling Language) [7, 9].

Unified Modelling Language (UML) adalah sebuah "bahasa" yang telah menjadi standar dalam industri untuk visualisasi, merancang dan mendokumentasikan sistem piranti lunak. UML menawarkan sebuah standar untuk merancang model sebuah sistem. Dengan menggunakan UML kita dapat membuat model untuk semua jenis aplikasi piranti lunak, dimana aplikasi tersebut dapat berjalan pada piranti keras, sistem operasi dan jaringan apapun, serta ditulis dalam bahasa pemrograman apapun. Tetapi karena UML juga menggunakan class dan operation dalam konsep dasarnya, maka UML lebih cocok untuk penulisan piranti lunak dalam bahasa - bahasa berorientasi objek seperti $C++$, Java, atau VB.NET. Walaupun demikian, UML tetap dapat digunakan untuk modeling aplikasi prosedural dalam VB atau C [9].

\section{METODOLOGI PENELITIAN}

\section{A. Algoritma RSA}

Sandi RSA merupakan algoritma kriptografi kunci publik (asimetris). Ditemukan pertama kali pada tahun 1977 oleh Ron Rivest, Adi Shamir, dan Len Adleman. Nama RSA sendiri diambil dari ketiga penemunya tersebut. Sebagai algoritma kunci publik, RSA mempunyai dua kunci, yaitu kunci publik dan kunci rahasia. RSA mendasarkan proses enkripsi dan dekripsinya pada konsep bilangan prima dan aritmetika modulo. Baik kunci enkripsi maupun dekripsi keduanya merupakan bilangan bulat. Kunci enkripsi tidak dirahasiakan dan diberikan kepada umum (sehingga disebut dengan kunci publik), namun kunci untuk dekripsi bersifat rahasia (kunci privat). Untuk menemukan kunci dekripsi, dilakukan dengan memfaktorkan suatu bilangan bulat menjadi faktorfaktor primanya. Kenyataannya, memfaktorkan bilangan bulat menjadi faktor primanya bukanlah pekerjaan yang mudah. Karena belum ditemukan algoritma yang efisien untuk melakukan pemfaktoran. Cara yang bisaa digunakan dalam pemfaktoran adalah dengan menggunakan pohon faktor. Jika semakin besar bilangan yang akan difaktorkan, maka semakin lama waktu yang dibutuhkan. Jadi semakin besar bilangan yang difaktorkan, semakin sulit pemfaktorannya, semakin kuat pula algoritma RSA.

Besaran-besaran yang digunakan pada algoritma RSA adalah:

- $\quad \mathrm{p}$ dan q bilangan prima (rahasia)

- $\mathrm{n}=\mathrm{p} \times \mathrm{q} \quad$ (tidak rahasia)

- $\varphi(n)=(p-1)(q-1)($ rahasia $)$

- e (kunci enkripsi / kunci publik) (tidak rahasia)

- $\quad \mathrm{d}$ (kunci dekripsi / kunci privat) (rahasia)

- $\quad \mathrm{P}$ (plainteks) (rahasia)

- $\mathrm{C}$ (cipherteks) (tidak rahasia)

Plain teks yang akan dienkripsi dengan RSA Coding merupakan angka-angka, sedangkan pesan yang dikirimkan bisaanya berbentuk teks atau tulisan. Sehingga dibutuhkan suatu kode yang sifatnya universal untuk mengubah pesan teks menjadi plain teks dalam bentuk bilangan. ASCII (American Standard Code for Information Interchange) atau Kode Standar Amerika untuk pertukaran informasi merupakan suatu standar internasional dalam kode 
huruf dan symbol seperti Hex dan Unicode tetapi ASCII lebih bersifat universal, contohnya 124 adalah untuk karakter "|". ASCII selalu digunakan oleh komputer dan alat komunikasi lain untuk menunjukkan teks.

Tabel 1. ASCII

\begin{tabular}{|c|c|c|c|c|c|c|c|c|c|c|c|c|c|}
\hline$\overline{D e c}$ & Hex & Name & Char & Ctrl-char & Dec & Hex & Char & Dec & Hex & Char & Dec H & Hex $\mathrm{C}$ & Char \\
\hline & & & & CTRL-@ & & 20 & Space & 64 & & (1) & & & \\
\hline 1 & 1 & Start of heading & SOH & CTRL-A & 33 & 21 & & 65 & 41 & & & 61 & a \\
\hline & 2 & Start of tent & STX & CTRL-B & 34 & 22 & & 66 & 42 & 8 & & $62 \mathrm{~b}$ & b \\
\hline 3 & 3 & $F$ & ETX & CTRL-C & 35 & 23 & " & 67 & 43 & & & $63 \mathrm{c}$ & c \\
\hline${ }_{5}^{4}$ & 4 & nd of: & EOT & CTRL-D & 36 & 24 & $\$$ & 68 & 44 & & & $64 d$ & d \\
\hline 5 & 5 & Enqui & ENQ & CTRL-E & 37 & 25 & $\%$ & 69 & 45 & E & 10165 & 65 & : \\
\hline & $\begin{array}{l}6 \\
7\end{array}$ & $\begin{array}{l}\text { Acknowedge } \\
\text { Bell }\end{array}$ & $\begin{array}{l}A \mathrm{AKK} \\
\mathrm{BEL}\end{array}$ & $\begin{array}{l}\text { CRRL-F } \\
\text { CTRL-G }\end{array}$ & 39 & $\begin{array}{l}26 \\
27\end{array}$ & 8 & $\begin{array}{l}70 \\
71\end{array}$ & $\begin{array}{l}46 \\
47\end{array}$ & ${ }_{G}^{F}$ & {$\left[\begin{array}{lll}102 & 66 \\
103 & 67\end{array}\right.$} & $\begin{array}{l}66 \\
67\end{array}$ & f \\
\hline & & & BS & CTRL-H & 40 & 28 & ( & $7_{72}^{1}$ & & & & & h \\
\hline & 9 & $t a b$ & HT & CTRL-1 & 41 & 29 & ; & 73 & 49 & 1 & & 69 & \\
\hline 10 & $O A$ & Line & LF & & 42 & $2 A$ & & 74 & $4 A$ & & $106 \quad 66$ & 6.4 & j \\
\hline $\begin{array}{ll}11 \\
11\end{array}$ & 08 & & & & 43 & $2 B$ & + & 75 & $4 \mathrm{~B}$ & k & $1076 \mathrm{E}$ & $6 \mathrm{~B} \quad \mathrm{k}$ & \\
\hline 13 & 足 & $\begin{array}{l}\text { Form feed } \\
\text { Carriage feed }\end{array}$ & $\begin{array}{l}F F \\
C R\end{array}$ & $\begin{array}{l}\text { CTRL-L } \\
\text { CTRL-M }\end{array}$ & $l_{45}^{44}$ & ${ }_{20}^{2 C}$ & : & 76 & $\begin{array}{l}4 C \\
40\end{array}$ & L & $\begin{array}{l}1086 \mathrm{c} \\
1096 \mathrm{c}\end{array}$ & $\begin{array}{ll}6 C & 1 \\
6 D & \end{array}$ & I \\
\hline & & $\begin{array}{l}\text { Carriage feed } \\
\text { Shift out }\end{array}$ & & CTRL-N & 45 & ${ }_{2 \mathrm{E}}^{20}$ & & 78 & 40 & ${ }_{N}^{M}$ & $\begin{array}{lll}109 & 60 \\
110 & 6 \mathrm{E}\end{array}$ & $\begin{array}{lll}60 & n \\
6 E & n\end{array}$ & $m$ \\
\hline 15 & of & $\begin{array}{l}\text { shift in } \\
\text { She }\end{array}$ & SI & CTRL -0 & 47 & $2 F$ & 1 & 79 & $4 F$ & 0 & 1116 & GF & 。 \\
\hline 16 & 10 & ne esce. & 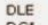 & CTRL-P & 48 & 30 & 0 & 80 & 50 & $p$ & & 70 & p \\
\hline & 11 & & & & 49 & 31 & 1 & 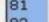 & 51 & $Q$ & 1137 & $\ldots$ & a \\
\hline $\begin{array}{l}18 \\
19\end{array}$ & ${ }_{13}^{12}$ & $\begin{array}{l}\text { Devic } \\
\text { Devic }\end{array}$ & $\begin{array}{ll}\mathrm{DC} 2 \\
\mathrm{DC} 3\end{array}$ & CTT & 50 & $\begin{array}{l}32 \\
33\end{array}$ & 2 & 82 & 52 & $R$ & 1147 & 72 & i \\
\hline${ }_{20}^{19}$ & $\begin{array}{l}13 \\
14 \\
14\end{array}$ & $\begin{array}{l}\text { Devict } \\
\text { Device }\end{array}$ & DC4 & & 51 & $\begin{array}{l}33 \\
34\end{array}$ & ${ }^{3}$ & 83 & 53 & s & $115 \%$ & 745 & s \\
\hline & $\begin{array}{l}14 \\
15\end{array}$ & $\begin{array}{l}\text { Device cont } \\
\text { Neg acknow }\end{array}$ & NAK & CTRL-U & 53 & $\begin{array}{l}34 \\
35\end{array}$ & $\begin{array}{l}4 \\
5\end{array}$ & $\begin{array}{l}84 \\
85\end{array}$ & $\begin{array}{l}54 \\
55\end{array}$ & u & $\begin{array}{l}1107 \\
117\end{array}$ & 75 & $\begin{array}{l}t \\
t^{2} \\
\end{array}$ \\
\hline & & & & & 54 & 36 & 6 & 8 & 56 & v & & 76 & \\
\hline 23 & $17 \mathrm{E}$ & En & $E$ & CTF & 55 & 37 & 7 & 87 & 57 & $w$ & & 77 & w \\
\hline $\begin{array}{l}24 \\
25\end{array}$ & 18 & & CAN & & 56 & 38 & 8 & 88 & 58 & $x$ & 1207 & 78 & \\
\hline & & End & & & 157 & & & 18 & & $Y$ & 1217 & 79 & y \\
\hline & ${ }_{18}^{18}-30$ & sut & $\begin{array}{l}\text { SUB } \\
\text { ESC }\end{array}$ & CTR & & 30 & & & $\begin{array}{l}5 A \\
5 B\end{array}$ & 2 & 1227 & $7 \mathrm{7A}$ & $z$ \\
\hline & $F_{1}$ & & & & & & & & & & & & \\
\hline 29 & io & Group separ & GS & CTR & 61 & 30 & $=$ & 93 & 50 & j & & 70 & 3 \\
\hline & 15 & Record sepes & $4 s^{\prime}$ & & & & & & SE & & & & \\
\hline & & & & & & & & & & & & & \\
\hline
\end{tabular}

\section{B. Model Pengembangan Sistem}

Dalam pembuatan aplikasi peningkatan keamanan pesan yang berbasis android ini penulis menggunakan model pengembangan system yaitu model RAD (Rapid Application Development). Berikut adalah tahapantahapan dan penjelasan pengembangan perangkat lunak dengan menggunakan model RAD (Rapid Application Development) $[7,8]$.

Model RAD memiliki 3 tahapan sebagai berikut :

1) Rencana Kebutuhan (Requirement Planning) Dalam fase ini, pengguna dan penganalisis bertemu untuk mengidentifikasikan tujuantujuan aplikasi atau sistem serta untuk mengidentifikasikan syarat-syarat informasi yang ditimbulkan dari tujuan-tujuan tersebut. Orientasi dalam fase ini adalah menyelesaikan masalah-masalah perusahaan.

2) RAD design workshop

Fase ini adalah fase untuk merancang dan memperbaiki yang bisa digambarkan sebagai workshop. Penganalisis dan pemrogram dapat bekerja membangun dan menunjukan representasi visual desain dan pola kerja kepada pengguna. Workshop desain ini dapat dilakukan selama beberapa hari tergantung dari ukuran aplikasi yang akan dikembangkan. Selama workshop desain RAD, pengguna merespon prototipe yang ada dan penganalisis memperbaiki modul-modul yang dirancang berdasarkan respon pengguna.

3) Implementasi (Implementation)

Pada fase implementasi ini, penganalisis bekerja dengan para pengguna secara intens selama workshop dan merancang aspek-aspek bisnis dan nonteknis perusahaan. Segera setelah aspek-aspek ini disetujui dan sistem- sistem dibangun dan disaring, sistem-sisem baru atau bagian dari sistem ujucoba dan kemudian diperkenalkan kepada organisasi.

\section{Metode Pengembangan Sistem}

Dalam penelitian kali ini, penulis menggunakan salah satu Metode Pengembangan Sistem yaitu Model RAD (Rapid Application Development).

RAD adalah suatu pendekatan berorientasi objek terhadap pengembangan sistem yang mencakup suatu metode pengembangan serta perangkat-perangkat lunak. RAD bertujuan mempersingkat waktu yang biasanya diperlukan dalam siklus hidup pengembangan sistem tradisional antara perancangan dan penerapan suatu sistem informasi. Pada akhirnya, RAD samasama berusaha memenuhi syarat-syarat bisnis yang berubah secara cepat.

\section{Tools Pengembangan Sistem}

Dalam penelitian ini penulis menggunakan tools pengembangan sistem UML (Unified Modelling Language) yang terdiri atas :

- Use case Diagram

Use case diagram dalam penelitian ini digunakan untuk menggambarkan aktivitas apa saja yang bisa dilakukan oleh user dalam aplikasi peningkatan keamanan pesan ini.

- Activity Diagram Activity diagram dalam penelitian ini digunakan untuk menggambarkan alur kerja sistem dalam aplikasi peningkatan keamanan pesan ini.

- $\quad$ Sequence Diagram

Sequence diagram dalam penelitian ini digunakan untuk menggambarkan skenario atau rangkaian langkah-langkah yang dilakukan sebagai respons dari sebuah event untuk menghasilkan output tertentu.

\section{HASIL DAN PEMBAHASAN}

Pada bagian ini akan menjelaskan hasil percobaan dan juga pembahasan dari penelitian ini,. Pada Penelitian ini algoritma yang digunakan adalah algoritma RSA, dimana Algoritma RSA merupakan algoritma asimetris yang menggunakan dua kunci berbeda untuk proses enkripsi dan dekripsi.

Perumusan Algoritma RSA

- Rumus Kunci Publik

Kunci publik (e) adalah kunci yang didapat dari hasil pemfaktoran $\varphi(\mathrm{n})$, yang relatif prima terhadap $\varphi(n)$. Misal $: \varphi(n)=(p-1) *(q-1)=(11-$ 1) $(13-1)=120$

Pemfaktoran dari 120 adalah 2, 3, dan 5. Karena nilai (e) tidak boleh sama dengan nilai hasil pemfaktoran, maka yang relatif prima terhadap 120 adalah 7 . Jadi, e $=7$ 
- Rumus Kunci Private

Setelah mendapatkan nilai dari kunci publik/kunci enkripsi (e), maka dapat ditentukan nilai kunci privat/kunci dekripsi (d) dengan menggunakan rumus:

$$
(e \cdot d) \bmod \varphi=1
$$

$$
d=\frac{1+\left(\mathrm{k}^{*} \varphi\right)}{\mathrm{e}}
$$

Pada rumus di atas nilai $\mathrm{k}$ adalah $1,2,3$,...dst, sampai hasil nilai $\mathrm{d}$ adalah bilangan bulat.

- Rumus Enkripsi

Setelah mendapatkan nilai kunci publik dan nilai privat, maka dapat dicari hasil enkripsi dengan rumus

$$
\mathrm{Ci}=\mathrm{Pi}^{\mathrm{e}} \bmod \mathrm{n}
$$

- Rumus Dekripsi

Untuk mencari nilai dekripsi, maka dapat dicari dengan rumus

$$
\mathrm{Pi}=\mathrm{Ci}^{\mathrm{d}} \bmod \mathrm{n}
$$

Analisis proses merupakan tahap menganalisis proses enkripsi dan dekripsi. Berikut ini cara mencarinya :

- $\mathrm{p}=11$

$$
q=67
$$

- $\mathrm{n}=\mathrm{p} * \mathrm{q}$

$$
\begin{aligned}
& =11 * 67 \\
& =737
\end{aligned}
$$

- $\varphi(\mathrm{n})=(\mathrm{p}-1)(\mathrm{q}-1)$

$$
\begin{aligned}
& =(11-1)(67-1) \\
& =(10)(66) \\
& =660
\end{aligned}
$$

- $\quad$ FPB $660=2^{2}, 3,5,11 \quad$ jadi $\mathbf{e}=\mathbf{1 3}$ 660<smiles>CC[181I-]CC</smiles><smiles>CCCC</smiles>

- $\mathrm{d}=1+(\mathrm{k} * \varphi)$

$$
\begin{aligned}
& \frac{\mathrm{e}}{\mathrm{d}=1+(9 * 660)} \mathrm{13}=\mathbf{4 5 7} \\
& \text { Plainteks }=\mathbf{M} \text { A R I N A } \\
& \mathrm{K}=\mathbf{1 3} \\
& \mathrm{Enkripsi}=\mathrm{Ci}=\mathrm{Pi}^{\mathrm{e}} \bmod \mathrm{n} \\
& \mathrm{C} 1=\mathrm{M}=77^{13} \bmod 737=\mathbf{2 2 0} \\
& \mathrm{C} 2=\mathrm{A}=65^{13} \bmod 737=\mathbf{3 8 4} \\
& \mathrm{C} 3=\mathrm{R}=82^{13} \bmod 737=\mathbf{1 5 8} \\
& \mathrm{C} 4=\mathrm{I}=73^{13} \bmod 737=\mathbf{5 0 8} \\
& \mathrm{C} 5=\mathrm{N}=78^{13} \bmod 737=\mathbf{1 2} \\
& \mathrm{C} 6=\mathrm{A}=65^{13} \bmod 737=\mathbf{3 8 4}
\end{aligned}
$$

Chipertext $=22038415850812384553$ 62166721

Dekripsi $=\operatorname{Pi}^{\mathrm{d}} \bmod \mathrm{n}$

$\mathrm{P} 1=220^{457} \bmod 737=77=\mathbf{M}$

$\mathrm{P} 2=384^{457} \bmod 737=65=\mathbf{A}$

$\mathrm{P} 3=158^{457} \bmod 737=82=\mathbf{R}$

$\mathrm{P} 4=508^{457} \bmod 737=73=\mathbf{I}$

$\mathrm{P} 5=12^{457} \bmod 737=78=\mathbf{N}$

$\mathrm{P} 6=384^{457} \bmod 737=65=\mathbf{A}$

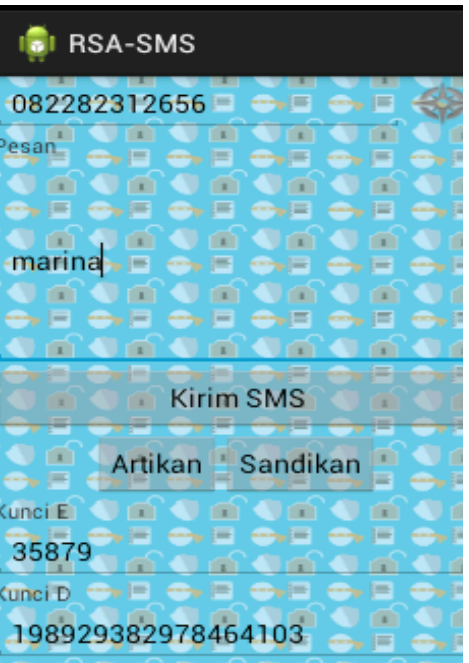

Gambar 1. Enkripsi dan Pengiriman Pesan Pada Android 


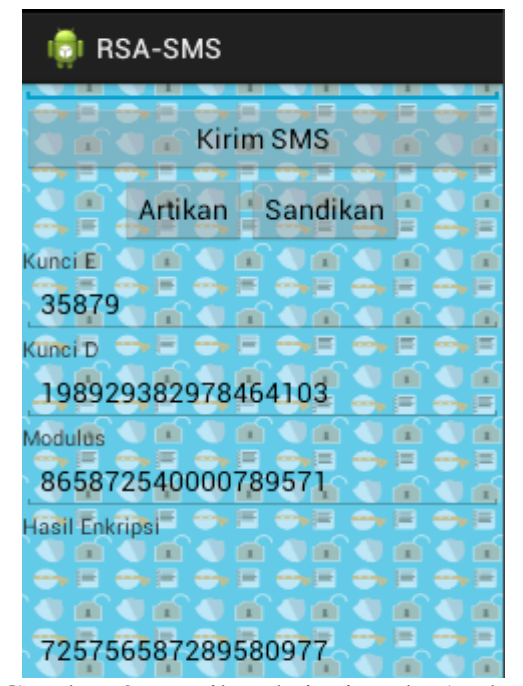

Gambar 2. Hasil Enkripsi pada Android

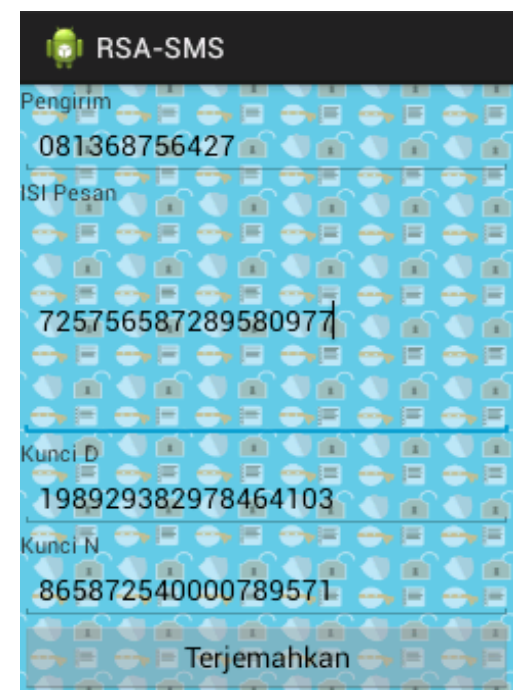

Gambar 3. Isi Pesan yang diterima

Pada gambar diatas merupakan contoh aplikasi yang dibangun untuk menguji coba algoritma RSA yang sudah diterapkan untuk mengamankan pesan pada android, disitu terlihat bahwa kita ambil contoh pesan dengan angka-angka acak dan juga kunci seperti yang diatas. Pada gambar - gambar diatas nampak bahwa pesan yang dikirim otomatis terenkripsi, dan juga pesan diterima juga masih dalam terenkripsi, sehingga jika ingin membuka pesan tersebut harus menggunakan kunci yang sesuai.

\section{PENUTUP}

\section{A. Kesimpulan}

Keamanan pesan berbasis android dapat dibuat dengan menggunakan aplikasi eclipse dengan menambahkan algoritma kriptografi RSA. Dan menambahkan fitur enkripsi dan dekripsi dalam aplikasi ini. Fitur enkripsi digunakan oleh pengirim untuk mengirim pesan dalam bentuk pesan rahasia dengan menggunakan key yang telah ditentukan oleh pengirim, dan fitur dekripsi digunakan oleh penerima untuk membuka pesan rahasia dengan key yang sama dengan yang digunakan pengirim yang telah dienkrip dan dikirim oleh pengirim.Algoritma kriptografi RSA ditambahkan dalam aplikasi ini guna meningkatkan keamanan pesan berbasis android dengan menerapkan algoritma RSA dalam proses mengenkripsikan pesan dengan menggunakan key yang berupa angka-angka yang telah ditentukan pengirim, dan mendekripsikan pesan yang dikirim menjadi pesan asli, sehingga pesan tersebut cukup aman dan tidak akan terbaca oleh pihak yang tidak mempunyai hak atas pesan tersebut.

\section{B. Saran}

Dari hasil pembahasan di bab-bab sebelumnya, ada beberapa saran yang penulis berikan untuk mengembangkan sistem yang penulis buat, yakni sebagai berikut:

- Dapat dikembangkan dengan menggunakan algoritma dan metode yang lainnya, sehingga keamanannya lebih terjamin.

- Diharapkan kedepannya aplikasi ini tidak hanya dapat mengamankan pesan saja, tetapi dapat mengamankan seperti data pemerintahan, email dan media informasi lainnya.

\section{DAFTAR PUSTAKA}

[1] Sulaiman R, Isnanto B, 2018, "Peningkatan Keamanan Pesan Dengan Kriptogafi RC4 dan Steganografi LSB Pada File JPEG”, Konferensi Nasional Sistem Informasi 2018

[2] Syahputra, Edi, 2013, "Pengembangan Aplikasi Pertukaran SMS Rahasia Berbasis Android Menggunakan Algoritma RSA", Institut Petanian Bogor (IPB), Bogor Agricultural University.

[3] Ginting, Albert, 2015, "Implementasi Algoritma Kriptografi RSA Untuk Enkripsi Dan Dekripsi Email”, Program Studi Sistem Komputer Fakultas Teknik Universitas Diponegoro, Jurnal Teknologi dan Sistem Komputer, Vol.3, No.2, April 2015, e-ISSN: 2338-0403.

[4] Fauzia, Rahma, Isna, 2015, "Rancang Bangun Aplikasi Enkripsi SMS (Short Message Service) Dengan Metode RSA Pada Telepon Selular Berbasis Android", Politeknik Negeri Malang, Prosiding Seminar Informatika Aplikatif Polinema 2015 (SIAP), ISSN: 2460-1160.

[5] Nidya, Agustina, Ardelia, 2017, "Pengamanan Dokumen Menggunakan Metode RSA (Rivest Shamir Adleman) Berbasis Web", Politeknik Negeri Sriwijaya Palembang, Prosiding Seminar Nasional Multi Disiplin Ilmu \& Call For Papers UNISBANK ke-3 (SENDI_U 3) 2017 ISBN : 9-7897936-499-93.

[6] Dewanto, I.Joko, 2013, "Pembuatan Aplikasi SMS Kriptografi RSA Dengan Android”, Universitas Esa Unggul, Forum Ilmiah Volume 10 Nomer 2, Mei 2013.

[7] Sutabri, Tata. 2012. Konsep Sistem Informasi. Yogyakarta: Andi Offset.

[8] Kendall, J.E. \& Kendall, K.E. 2010. Analisis dan Perancangan Sistem. Jakarta: Indeks.

[9] Sulaiman R, Isnanto B, 2016, "Pembuatan Sistem untuk Peningkatan Kualitas Layanan Pada Lembaga Pendidikan Komputer XYZ" , Jurnal Teknologi Informatika dan Komputer Atma Luhur Vol 3. No 1. Maret 2016 ISSN: 24067962 